\title{
Research on the Reform of Practical Teaching Driven By Practical Training under Constructivism
}

\author{
XinLiang Ou ${ }^{\text {a, }}$, John Wang ${ }^{\text {a }}$, Huafu Liu ${ }^{a}$, Dan Wen ${ }^{\text {a }}$, Wende He ${ }^{\text {a }}$, Yi Pan ${ }^{\text {a }}$ \\ ${ }^{a}$ Dept. of Computer Science \& Technology, Changsha University, Changsha, China
}

\begin{abstract}
Reform of practical teaching driven by practical training with real projects is a reform to improve every aspect of practical teaching by introducing, processing and decomposing real world projects to create real cases for teaching. In this article, the current reforming process of practical teaching in the area of computer science is analyzed from the point of view of a constructivist. In regard of the characteristics of the educational system in computer science, we also discussed how to organize and implement such enterprise-level project-driven practical teaching under the guidance of constructivism theory.
\end{abstract}

Index Terms: constructivism; practical teaching;practical training; college enterprise cooperation

(C) 2011 Published by MECS Publisher. Selection and/or peer review under responsibility of the Research Association of Modern Education and Computer Science.

\section{Background of reform}

From the year 2000, because of the global adjustment of IT industry, and because of the aging educational model, more and more students majored in computer science can not meet the need of social economic growth, the result is that the students experience the pressure of employment and IT enterprises struggle to find qualified engineers.

In recent years, after communicating with IT enterprises and gathering feedbacks from students, we have learned that computer-majored students face the following problems in the market.

First, students' professional knowledge and market needs are not necessarily on the same track, the courses contains too much basic knowledge, the corresponding experiments focus more on verification and less on design and composition, more exercises and experiments are designed to understand and verify knowledge, and less come from real world software development. Therefore, students feel a great distance between the knowledge taught and the professional knowledge required to develop software, skills for real software development are either not taught or not included by core courses.

\footnotetext{
* Corresponding author.

E-mail address: ox1888@ @om.com
} 
Second, school students do not have contact with corporate culture, environment, work flow and management. They also lose contact with software development knowledge structure, skill, and comprehensiveness. Knowledge learned in school is classified into different "courses", but its application is goal oriented, problem solving could involve different categories of knowledge with different depth and width.

Third, graduation fieldwork is insufficient. The topic of graduation project is usually outdated, designed by the teachers, big and out of focus. The design requirements and administrative regulations are so different from those of an enterprise. Students are trained under no division of work, no schedule, no regulation and no discipline.

Four, the practical content of courses, curricula projects and graduation project are dealt with individually, not progressively as from verification to design, then to combinatorial training, not treated as a real world development project, not united with practical teaching, therefore, not forming part of the educational system with the goal to produce applied talents.

Fifth, Chinese IT enterprises are usually small in scale and relatively weak. They prefer qualified employees who do not need too much corporate training.

To solve the above problems, we carefully analyze the goal and the plan of teaching, closely follow the theory of constructivism, and propose a reform to drive practical teaching with practical training using realistic industrial projects. It guides us to make a new teaching plan in the field of computer science and technology and to develop students' ability to learn, practice and create. It also helps us to form a practical educational system. In the new system, teaching becomes a progressive and integral process, with experiment, practice and training as integral parts of one process. In reality, the result of reform is promising (In 2005, it becomes a provincial education reform project). Under the guidance of constructivism, with the model of taskdriven teaching, the reformed project-oriented practical training puts practical teaching in the right position and shows the characteristics of project-based educational activity. With industrial project oriented practical training as a driving force to reform the current practical teaching system, experiments, curricula projects, fieldworks and even graduation project are all connected by realistic industrial projects. The comprehensiveness and progressiveness are gradually improved. Under the instruction of teachers, students are able to acquire systematic professional knowledge and develop industry level skills. Following to the schedule of development project, we see modifications of three aspects of teaching: from theory-centered practical teaching to realistic industrial application oriented practical teaching, from pure knowledge reception to comprehensive development, from basic and extensive knowledge covering to IT profession targeting.

The comprehensive experiments of experiment classes are designed after real industrial projects. The content of curricula designs also comes from those projects except that its comprehensiveness is higher than that of comprehensive experiments.

\section{Constructivism Education Theory and Practical Training Driven by Real Industrial Projects}

\subsection{Introduction of Constructivism Education Theory}

Constructivism is a branch of cognitive psychology, a popular educational theory formed during the 60s of the twentieth century. Constructivist believes that knowledge is constructed individually, that acquirement of knowledge is an active process of a learner, not a passive one. New knowledge can be truly absorbed only after the learner has processed and transformed its structure. Constructivist emphasizes the activeness of the learning party and believes that knowing is from inside out, that knowing is a process to combine current setting with past experiences of the learning subject and that a teacher should be an organizer and director in this learning process[1].

The design of constructivist teaching follows these principles: learning is driven by solving problems which could be projects, cases or real world problems; all the teaching activities are centered round the student and they are just a generalized environment to support, induce and stimulate active learning, the learner quickly takes the problem as her own and tries to actively solve it; the problem solved must be a realistic task in a 
realistic setting; cooperation is emphasized in the learning process; holistic evaluation is also emphasized; varieties of strategies are designed to let students spontaneously finish the task by using related resources, tools and helps in the learning environment, generously speaking, students should conduct research spontaneously, communicate with each other and continuously solve difficult problems under the guidance of a teacher in a realistic environment, the result is the structure of knowledge gets constructed[2].

\subsection{Analysis of the Reform of Project Driven Practical Teaching}

- From constructivism theory, we have the idea to reform practical teaching by using realistic projects.

- The content of experiment class is no longer mere understanding concept, proving theory, testing algorithm, but key knowledge points needed by the practical training projects, either already developed or currently being developed, students are situated in an enterprise environment, getting trained as if they are employees; the realness of graduation project is emphasized, that is, realistic development in realistic project. In this system of practical teaching, the reformed teaching is driven by the realistic projects and under the guidance of teachers, students are grouped into different teams based on different interests, there are team works, new skills are developed spontaneously, new knowledge is acquired on one's own, problems are found and solved, finally the construction of knowledge and skills is completed.

- The goal of the reform of practical teaching driven by realistic projects is of the realization of the transformation from "focusing on the verification of theory and overseeing their applications" to "emphasizing the importance of project-driven education with theoretical knowledge as assistance". The content of experiments is centered round realistic projects, leading students to actively explore, solve problems and construct knowledge system of their own in a meaningful way. Case studies of curricula designs come from sub-problems of realistic projects, students use learned knowledge comprehensively to solve real problems, find new problems and accomplish assigned tasks. The project-driven practical training is conducted in a corporate environment. Students are grouped up into teams, participating in designs. Teacher leads in the process, providing guidance, help and evaluation. After this process, different kinds of knowledge learned in many courses get connected and applied.

- The goal of the reform of practical teaching driven by realistic projects is the realization of the transformation from "teaching knowledge by teachers and passively accepting knowledge by students" to "spontaneously constructing knowledge by students and guiding the process of the construction by teachers". At present time, students are high on scores and low on skills, the precollege test-oriented education drives students relying excessively on teachers, they treat textbook as dogma and receive knowledge passively, they possess low aptitude to solve real world problems using theoretical knowledge; the content of industrial project driven practical teaching comes from realistic projects, students are motivated, the proposal of how to solve problems is designed by the students themselves, students actively ask the teacher for instructions when difficulties are met, tasks are completed by students collaboratively, knowledge is constructed in the process of solving real world problems, the abilities of students are developed and improved.

- The goal of the reform of practical teaching driven by realistic projects is of the realization of the transformation from "education emphasizing the basics with a wide variety of knowledge being covered" to "education aiming at professional positions". Different categories of technologies are chosen by cooperating with companies with those particular technologies. Projects are technical and separated into modules. Students may team up and select from wide varieties of subjects, and eventually be well adapted to the professional positions.

Because our practical training is conducted in a real industrial environment, students could experience corporate culture, get familiar with the workflow of software development and gather precious experiences. 


\section{Implementation of the Reform of Project Driven Practical Teaching}

With practical training as a breaking point, the overall reform of practical training system will be realized. Three levels of practical teaching, i.e. experiment, fieldwork and practical training, are coexisting. The reforms are undertaken towards teaching plan, course syllabus, experiment syllabus, faculty hiring plan, laboratory construction plan, training base construction plan and school corporate cooperation strategy. With three levels of practical teaching combined in their entirety, a new practical teaching system is formed to develop students' ability to study, practice, innovate[3].

Below is a three-tiered hierarchical structure to show practical teaching system under reform and driven by practical training(Fig.1):

\begin{tabular}{|l|}
\hline Project-driven fieldwork and training \\
\hline Curriculum design based on project sub-modules \\
\hline Experiments on solving problems from project brought-downs \\
\hline
\end{tabular}

Fig. 1 Practical teaching system architecture

1) Experiments courses: Transform from experiments of pure theory verification including concepts, principles and algorithms to experiments on solving problems out of project brought-downs. Increase project related designing and comprehensive type of experiments. Require students to apply concepts, principles and algorithms learned from various courses. Regulate and consolidate the content of core course and required course related experiments. Principal teachers are responsible to edit practical teaching related part of course syllabus, to clarify the content of course, style of teaching and credits of course. That part of the syllabus should be evaluated and approved by academic committee of the department and archived. Any teacher who teaches that course should follow the syllabus closely. For the courses with changing content, combine the required programs with elective programs and leave the contents of experiments relatively fairly fixed in accordance with the relatively stable content of the course. The teacher is allowed to adjust the rest of the contents, provided she chooses project related problems as case studies as many as possible.

\section{2) Reform of curriculum design}

In curriculum design, it is required that tasks come from sub-problems, sub-systems or sub-modules of realistic projects. The goal is to let students solve real world problems and improve design and development capabilities. Under the guide of teachers, students will finish the tasks by themselves with team work.

Curriculum design schedule is evaluated by the department. At least 50\% of the tasks should come from real projects. Teacher should edit the syllabus, choose the tasks and define the way how tasks are finished. The whole process is divided into three parts: assignment by the teacher, designing and programming by the students and evaluation by the teacher. Students finish the tasks spontaneously while the teacher gives directions in the process.

Practical training is conducted in training facilities, and it progresses in stages. Some students participate in on-going development projects in the companies which are later responsible to host those students' graduation practical training and graduation design. Some other students receive training in the off-campus training bases sponsored by both corporations and school, the projects used for training are sub-systems decomposed from successful industrial projects. The rest of the students receive training in the on-campus training bases built by school and corporations with housing provided by school and equipment, software, management and part of training staff provided by corporations.

The school training base is built in our department as an achievement of cooperation with Software City in Changsha high-tech district. We provide training spaces and they design training goals (after negotiation), training plans and training procedures. They provide development platforms, raining cases and trainers. This is an important multi-level, multi-form collaboration with the National Software Development Facility in Changsha. On this platform consisted of government, IT industry and college, resources and information are 
shared efficiently. With communication between college and IT industry and services provided by the government, valuable trials to develop IT professionals is promoted.

Project driven practical training is an intersection of higher education and requirement of IT enterprises. It is a warm-up training for students before they become IT professionals. Its goal is to develop engineers on both software development and hardware development. Taking software engineer development as an example, the following are the aspects of training in detail:

a) learning the regularization, specialization, standardization and scale of development project workflow;

b) experiencing different roles in a typical IT project developing team and learning the skills of cooperation of the roles in a team;

c) learning and practicing current mainstream software development methodologies and their applications in IT projects;

d) learning and practicing current mainstream software developing tools and their applications in software development processes;

e) learning and experiencing the applications of classroom theoretical knowledge in real world projects, gathering hands-on experiences;

f) learning and experiencing CMM standards and their applications on controlling software development processes;

g) experiencing corporate culture and IT company's requirements of knowledge structure, technical skills, and comprehensive quality of employees

h) transforming student's status from a student to an employee smoothly, strengthen student's competitive capability and elevating student's confidence.

Other than the above, we also strengthen the faculty in order to accomplish the reform of practical teaching system. By hiring new teacher, school corporate double employing and self-developing, an academic, hierarchically structured, high-quality faculty is built, led by academic leaders. We hold the principle that the whole faculty is guided by the leader, the key faculty is the main force, emphasizing the development of 'dualfunction' teachers and combining academic and industrial characteristics. To the current faculty, we emphasize the development of practical skills and comprehensive qualities, emphasize the importance of knowledge updates, periodically assign teachers to varieties of technical trainings and make regulations financially supporting young teachers to work, train and accumulate practical working experiences in corporations. We also make regulations to encourage teachers to update their knowledge consistently, to improve themselves, to assist each other. We hire or develop new academic leaders and let current academic leaders play important roles.

\section{Workflow of project-driven practical training}

Project-driven practical training follows the path of the driving project, combined with the application of professional knowledge in IT development and management, inducing a variety of key knowledge and skills, making up training programs systematically. The important phases of training include forums and lectures on key knowledge and technologies, requirement analysis of projects, preliminary design and detailed design, coding and testing, system integration and testing, product evaluation and final grading. A trainee moves to the next phase only after examination (see Fig. 2). 


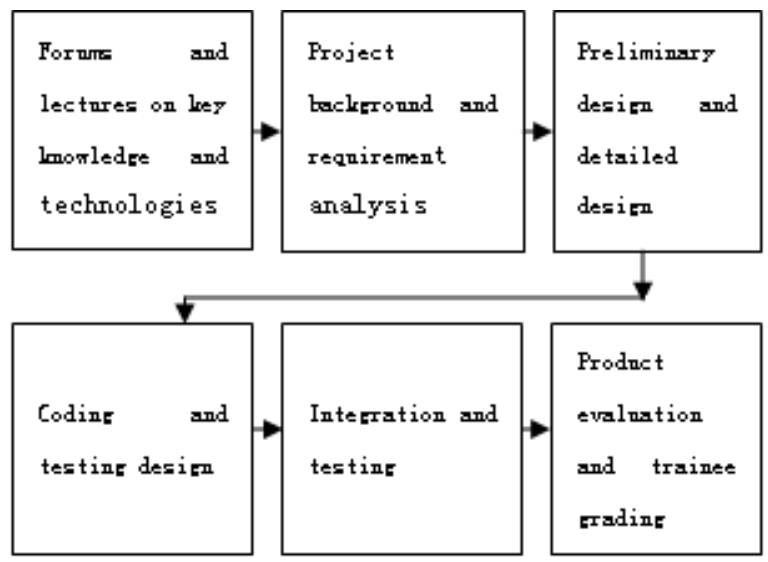

Fig. 2 workflow of project-driven practical

The training produced products are published and evaluated by corporations and training bases. This helps trainees to find their own problems, accumulate software development experiences and develop their development techniques. At the same time the effectiveness of training are evaluated by both IT professionals and trainees. This lets the students experience the requirements and regulations of real IT development projects. Training instructors are made of experienced project managers and technicians in IT industry.

\section{Result of Reform}

After the first practical training, we distributed 100 questionnaires among which 90 were collected. The feedback of the practical training is as of Table 1. Later feedback survey of training was conducted from 2008 to 2010, the results shown in Table 2.

Table 1 Feedback of practical training (A: Very Satisfied; B: Satisfied; C: Mediocre; D: Unsatisfied)

\begin{tabular}{|l|l|l|l|l|l|}
\hline \multirow{2}{*}{ Major } & \multirow{2}{*}{ Num } & \multicolumn{4}{|l|}{ Satisfaction } \\
\cline { 3 - 6 } & & A & B & C & D \\
\hline CS Tech & 56 & 11 & 18 & 18 & 9 \\
\hline CS App & 34 & 5 & 11 & 15 & 3 \\
\hline Total & 90 & 16 & 29 & 33 & 12 \\
\hline Ratio & $100 \%$ & $17.7 \%$ & $32.2 \%$ & $36.4 \%$ & $13.3 \%$ \\
\hline
\end{tabular}

Table2 Practical training feedback of graduation year 2008, 2009 and 2010

\begin{tabular}{|l|l|l|l|l|l|}
\hline \multirow{2}{*}{ Graduation } & \multirow{2}{*}{ Num } & \multicolumn{4}{|l|}{ Satisfaction } \\
\cline { 3 - 6 } & & A & B & C & D \\
\hline \multirow{2}{*}{2008} & \multirow{2}{*}{156} & 41 & 70 & 35 & 10 \\
& \multirow{2}{*}{2009} & $26.3 \%$ & $45 \%$ & $22.4 \%$ & $6.3 \%$ \\
\hline \multirow{2}{*}{2010} & 90 & 111 & 10 & 13 \\
& \multirow{2}{*}{190} & $50 \%$ & $49.5 \%$ & $4.5 \%$ & $6 \%$ \\
\hline Trends & & $26.3 \%$ & 109 & 23 & 8 \\
& & $\sim$ & $\nearrow$ & $\sim$ & $\searrow$ \\
\hline
\end{tabular}


The result of first practical training indicates that students who had followed the procedure closely showed stronger competitiveness, for example, Han Long, a 2003 year student in class 1 who was pursuing the Bachelor's Degree in Computer Science and Technology was employed by the Shanghai Lianchuang Technologies when facing fierce competitions, that is, one out of twenty, he believes the reason is that he has acquired more industrial project development experience in the practical training. Other students like Yuan Ping, Zhou Lingjie, 2004 year students in class 4 who were pursuing the College Degree in Computer Application were also hired by some excellent firms. They believe they were benefitted from the industrial experiences acquired from the practical training.

But problems emerged, one is the shortage of training personnel, the other is lack of commitments of students who do not have enough knowledge to face industrial challenges, the third is the over-simplicity of training projects, and the fourth, low student satisfaction rate.

a) the professional knowledge of students is not solid enough. They face a tremendous challenge in the training process. Students are too scared to participate in the training.

b) students do not feel comfortable to change their status from students to employees. It is difficult for them to fit into the enterprise management model.

c) no adequate publicity of practical training is originated from the department.

d) students do not know yet what kind of employees the enterprises are looking for.

e) improvement of training environment, training personnel and training projects are still anticipated.

We have adopted the measures to improve teaching personnel, to increase the percentage of teachers working both at school and in corporation and to strengthen the cooperation between school and corporation. We have improved school teaching by bringing project-oriented key knowledge and technologies into curricula designs and by emphasizing the evaluation of curricula designs. We have perfected the practical training by inducing industrial projects from multiple corporations and by breaking up those projects into cases used by practical training. We have also let practical training receive enough publicity and let students receive adequate practicing and experience enough corporate cultures in the IT industry before they start the training. Practical teaching is a key part of engineering education[4]. It is long, complicated, systematic and cooperative process to reform teaching, to develop students' engineering qualities and to strengthen their selfteaching, problem-solving and creative abilities. As long as we persist to explore and innovate in the aspects of education theory, model, architecture, content and methodology, we will be confident to find an appropriate and applicable way to do so.

\section{References}

[1] Xifa Liu, Jiali Xia. "Project-driven" teaching model guided by constructivism. Telecommunication Education Research, 2007, (8):65-67(in Chinese)

[2] Gaofeng Zhu. Achievements, Problems and Strategies of Chinese Engineering Education. Advanced Engineering Education Research. 2007,(4):1-7(in Chinese)

[3] Zhipan Ye, Peihua Jin. Summary of Practical Teaching of Chinese Engineering Education[J]. Advanced Engineering Education. 2007,(4):74-77(in Chinese)

[4] JohnMalmqvist, KristinaEdstr.m, Svante Gunnarsson, S.ren.stlund.The application of CDIO Standards in the evaluation of Swedish engineering degree programmes.World Transaction on Engineering and Technology Education, 2006: 361-364. 